East African Medical Journal Vol. 80 No. 12 December 2003

ENTEROTOXIGENICITY AND DRUG SENSITIVITY OF STAPHYLOCOCCI FROM CHILDREN AGED FIVE YEARS AND BELOW WITH SPORADIC DIARRHOEA

M.O. Efuntoye, Department of Biological Sciences, Ogun State University, P.M.B. 2002, Ago-Iwoye, Nigeria and A.I. Adetosoye, Department of Veterinary Microbiology and Parasitology, University of Ibadan, Ibadan, Nigeria

Request for reprints to: Dr. M.O. Efuntoye, Department of Biological Sciences, Ogun State University, P.M.B. 2002, Ago-Iwoye, Nigeria

\title{
ENTEROTOXIGENICITY AND DRUG SENSITIVITY OF STAPHYLOCOCCI FROM CHILDREN AGED FIVE YEARS AND BELOW WITH SPORADIC DIARRHOEA
}

\author{
M.O. EFUNTOYE and A.I. ADETOSOYE
}

\begin{abstract}
Objective: To investigate the incidence of enterotoxigenic strains of staphylococci in children aged five years and below suffering from sporadic diarrhoea and their antibiotic susceptibility pattern.

Design: Collection of stool samples from children with sporadic diarrhoea and laboratory based microbiological analysis.

Setting: Microbiology Research Laboratory, Department of Veterinary Microbiology and Parasitology, University of Ibadan, Ibadan, Nigeria.

Results: Out of one thousand seven hundred and sixty one diarhoeic faecal specimens collected, one hundred and seven strains of staphylococci were isolated as pure culture. Seventy two of these 107 staphylococci were coagulase positive $S$. aureus, 33 strains were S. epidermidis and two strains were S. saprophyticus. Sixty one $(\mathbf{8 4 . 7 \%})$ of 72 isolates of $S$. aureus produced enterotoxins. Staphylococcal enterotoxins A was produced singly by $37(60.7 \%)$ of the toxigenic strain, while $12(19.7 \%)$ produced enterotoxin $D$ alone. Two strains produced both enterotoxins $A$ and $C$, six strains produced both enterotoxins $A$ and $D$, one strain produced enterotoxins $A, C$ and $D$ while two strains produced enterotoxins A, B, and D. Most strains were resistant to pennicilin, with minimum inhibitory concentrations (MIC) within the range of $1-16 \mu \mathrm{g} / \mathrm{ml}$.

Conclusion: Enterotoxigenic strains of $S$. aureus were recovered from children aged five years and below suffering from sporadic diarhoea. The incidence rate was $3.5 \%$ of the samples investigated. Results of their antibiogram revealed that chloramphenicol, gentamicin, cephalothin and clindamycin would be appropriate for treatment of such diarrhoea after the clinical value of the antibiotics in young children has been evaluated.
\end{abstract}

\section{INTRODUCTION}

Infectious diarrhoea constitutes the leading cause of both morbidity and mortality among infants and children in the developing countries. Rotavirus, enterotoxigenic E. coli (ETEC), Campylobacter jejuni and Salmonella and Shigella species have been identified as causes of diarrhoea in children(1).

There is no known work in Nigeria on the aetiologic role of $S$. aureus in diarrhoea affecting children aged five years and below. However Adekeye and Adesiyun (2) and Olowe et al.(3) isolated S. aureus from milk of nursing mothers in Kaduna and Lagos States of Nigeria respectively. Adekeye and Adesiyun (2) found no direct relationship between enterotoxigenic staphylococci in the milk of nursing mothers and diarrhoea in the children in their investigation. However they showed that there was a potential health risk in the children from whom staphylococci were isolated. $\mathrm{S}$. aureus is becoming an increasingly important agent of food borne disease. It was therefore considered pertinent to investigate, in a cross-sectional study, the incidence of enterotoxigenic strains in children with sporadic cases of diarrhoea. A knowledge of the antibiogram is also desirable especially in the wake of developing resistance to antibiotics by bacteria isolated from the colon(4).

\section{MATERIALS AND METHODS}

One thousand seven hundred and sixty one freshly voided faecal samples from diarrhoeic children aged five years and below were collected from five hospitals located in Ibadan, Nigeria. Samples were collected from one thousand seven hundred and sixty one children ( 822 males and 939 females) with isolated incidents of acute diarrhoea illness reported in the hospitals over a nine month period. The samples were processed within two hours of collection for the isolation of bacteria. One gram of each faecal sample was suspended in sterile distilled water and direct plating and enumeration of S. aureus were done on Baird-Parker agar (BBL11022). In addition tripticase soy agar with $10 \% \mathrm{NaCL}$ into which 5\% sheep and human blood was added respectively were also used. All plates were incubated at $37^{\circ} \mathrm{C}$ for 24 hours. Plates were examined for colonial characteristics 
typical of the staphylococci. Plates in which only staphylococci were isolated exclusive of other pathogens were studied further. Strains were identified and biochemically characterised using conventional methods described in Barrow and Feltham (5). Each strain was analysed for catalase activity. Clumping factor was determined by the slide test and the coagulase test was done with rabbit plasma. DNAase and thermonuclease activities were determined by the methods described by Adegoke(6).Other characteristics determined were staphylokinase production(7), aesculin hydrolysis, urea hydrolysis, acetylmethyl carbinol production, reduction of nitrate, oxidase activity, alkaline phosphatase production, growth in thioglycollate medium and fermentation of sugars such as glucose, fructose, mannose, maltose, mannitol, trehalose, xylose, sucrose, lactose, cellobiose and arabinose. Species differentiation/identification of S.epidermidis and S. saprophyticus was done using biochemical tests such as $B-$ galactosidase production, acid production from turanose and mannose and alkaline phosphatase production.

Toxin production in-vitro: The "SET-RPLA" kit (Oxoid, UK) that relied on rapid reversed agglutination to detect enterotoxins in S. aureus was used. Seventy two strains of $S$. aureus were tested. Results were interpreted according to the manufacturer's recommendations.

Antibiotic susceptibility testing: The antibiotic susceptibility testing was carried out on Diagnostic Sensitivity Test (DST) agar (Oxoid, UK). The inoculum and the antibiotic sensitivity test were prepared according to the method of Adetosoye et al.(8). One hundred and seven staphylococcal isolates were tested using antimicrobial agents including penicillin (10 units), chloramphenicol $30 \mu \mathrm{g}$, colistin $10 \mu \mathrm{g}$, kanamycin $30 \mu \mathrm{g}$, ampicillin $10 \mu \mathrm{g}$, erythromycin $15 \mu \mathrm{g}$, clindamycin $2 \mu \mathrm{g}$ and methicillin $5 \mu \mathrm{g}$ (Difco). The zones of inhibition around the antibiotic discs were measured in millimeter and zones of inhibition recommended by NCCLS (9) were used to classify the strains as resistant, sensitive or moderately resistant.

The minimum inhibitory concentration (MIC) of penicillin, and erythromycin was determined for S. aureus which showed resistance to them. The MICs were determined by microtitre method as described by Adetosoye et al. (10). The MIC of each antibiotic was taken as the minimum amount of antibiotic needed to inhibit the growth of the isolate under test and it was indicated by no change in colour of the indicator. For a series of tests Oxford Staph (NCTC 6571) was used as control.

\section{RESULTS}

In this investigation, 72 of the 107 staphylococci isolated were coagulase positive strains while 33 were identified as S. epidermidis and two were identified as S. saprophyticus. These staphylococci species occurred respectively at the frequency of $67.2 \%, 30.84 \%$ and $1.87 \%$ of the total staphylococcal isolates (Table 1).

None of the isolates fermented arabinose. Fifty two of the coagulase positive staphylococci produced deoxyribonuclease. Thermostable nuclease was produced by 50 strains of $S$. aureus.

Sixty one (84.7\%) of the $S$. aureus strains examined were enterotoxigenic. The distribution of enterotoxigenic S. aureus in different age groups is shown in Table 2.
There appeared to be no significant difference in distribution of enterotoxigenic $S$. aureus between the males and females examined. Enterotoxins A, B, C and $\mathrm{D}$ were detected in supernatants. Thirty seven strains produced enterotoxin A while 12 strains produced enterotoxin $\mathrm{D}$. Twelve strains produced multiple enterotoxin (6 AD, 2 AC, 1 ABC, 2 ACD and $1 \mathrm{ABCD}$ ) and eleven strains were non-enterotoxigenic (Table 3 ).

\section{Table 1}

Frequency of Staphylococcus species in diarrhoeic faecal samples of children $(\mathrm{n}=1761)$

\begin{tabular}{lll}
\hline Species & No. of strains & $\%$ \\
\hline S. aureus & 72 & 4.08 \\
S. epidermidis & 33 & 1.87 \\
S. saprophyticus & 2 & 0.11 \\
\hline Total & 107 & 6.07 \\
\hline
\end{tabular}

Table 2

Distribution of $S$. aureus by age group and gender

\begin{tabular}{lll}
\hline \multicolumn{2}{c}{$\begin{array}{c}\text { No. of samples positive for } \\
\text { Male }\end{array}$} & $\begin{array}{c}S \text { aureus* } \\
\text { Female }\end{array}$ \\
\hline$<1$ & $198 / 5(5)$ & $218 / 6(6)$ \\
$1.1-2.0$ & $151 / 6(5)$ & $172 / 7(7)$ \\
$2.1-3.0$ & $149 / 6(6)$ & $160 / 6(4)$ \\
$3.1-4.0$ & $138 / 7(5)$ & $154 / 8(5)$ \\
$4.1-5.0$ & $186 / 10(8)$ & $235 / 11(10)$ \\
\hline Total & $822 / 34(29)$ & $939 / 38(32)$ \\
\hline
\end{tabular}

*Data are no. of samples tested/no. positive

Numbers in parentheses are enterotoxigenic strains

Table 3

Distribution of enterotoxin types a produced by S. aureus isolated from children with diarrhoea

\begin{tabular}{lcc}
\hline Toxin type & Positive/Total tested & $\%$ positive \\
\hline $\mathrm{A}$ & $37 / 72$ & 51.4 \\
$\mathrm{D}$ & $12 / 72$ & 16.7 \\
$\mathrm{AC}$ & $2 / 72$ & 2.8 \\
$\mathrm{AD}$ & $6 / 72$ & 8.3 \\
$\mathrm{ABC}$ & $1 / 72$ & 1.4 \\
$\mathrm{ACD}$ & $2 / 72$ & 2.8 \\
$\mathrm{ABCD}$ & $1 / 72$ & 1.4 \\
\hline Total & $61 / 72$ & 84.7 \\
\hline
\end{tabular}

a Isolates were tested for production of enterotoxins A, B, $\mathrm{C}$ and $\mathrm{D}$

The results of in-vitro antibiotic susceptibility testing of coagulase positive and coagulase negative isolates are shown in Table 4. Most coagulase positive strains were sensitive to gentamycin, cephalothin, kanamycin, clindamycin, chloramphenicol and methicillin and were resistant to ampicillin, erythromycin, polymyxin $B$ and penicillin. 
Table 4

Antibiotic susceptibility patterns of coagulase positive and negative staphylococcal isolates

\begin{tabular}{|c|c|c|c|c|}
\hline \multirow[b]{2}{*}{ Antibiotic } & \multicolumn{2}{|c|}{ Coagulase-positive } & \multicolumn{2}{|c|}{ Coagulase-negative } \\
\hline & $\begin{array}{l}\text { No. of } \\
\text { isolates } \\
\text { tested }\end{array}$ & $\begin{array}{l}\text { No. } \\
\text { resistant } \\
(\%)\end{array}$ & $\begin{array}{l}\text { No. of } \\
\text { isolates } \\
\text { tested }\end{array}$ & $\begin{array}{l}\text { No. } \\
\text { resistant } \\
(\%)\end{array}$ \\
\hline Ampicillin, $10 \mu \mathrm{g}$ & 72 & $57(79.17)$ & 26 & $16(61.54)$ \\
\hline Colistin, $10 \mu \mathrm{g}$ & 72 & $71(98.61)$ & 26 & $26(100)$ \\
\hline Gentamicin, $10 \mu \mathrm{g}$ & 72 & $0(-)$ & 26 & $0(-)$ \\
\hline Cephalothin, $30 \mu \mathrm{g}$ & 72 & $0(-)$ & 26 & $0(-)$ \\
\hline Erythromycin, $15 \mu \mathrm{g}$ & 72 & $48(66.67)$ & 26 & $17(65.38)$ \\
\hline Kanamycin, $30 \mu \mathrm{g}$ & 72 & $16(22.22)$ & 26 & $4(15.38)$ \\
\hline Polymyxin $\mathrm{B}, 300 \mu \mathrm{g}$ & 72 & $71(98.61)$ & 26 & $1(3.85)$ \\
\hline Clindamycin, $2 \mu \mathrm{g}$ & 72 & $3(9.17)$ & 26 & $1(3.85)$ \\
\hline Penicillin $G, 10$ units & 72 & $72(100)$ & 26 & $7(26.92)$ \\
\hline Chloramphenicol, $30 \mu \mathrm{g}$ & 72 & $0(-)$ & 26 & $0(-)$ \\
\hline Methicillin $5 \mu \mathrm{g}$ & 72 & $5(6.94)$ & 26 & $2(7.69)$ \\
\hline
\end{tabular}

Table 5

Minimum inhibitory concentrations (MICs) of some antibiotics for S. aureus isolates

\begin{tabular}{|c|c|c|c|c|c|c|c|c|c|c|}
\hline \multirow[b]{2}{*}{ Antibiotic } & & \multicolumn{7}{|c|}{ MIC } & \multirow[b]{2}{*}{1} & \multirow[b]{2}{*}{0.5} \\
\hline & & 128 & 64 & 32 & 16 & 8 & 4 & 2 & & \\
\hline Ampicillin & No. & - & - & - & - & 45 & 6 & 5 & 1 & - \\
\hline$*$ No. $=57$ & $\%$ & & & & & 78.9 & 10.5 & 8.7 & 1.7 & - \\
\hline Erythromycin & No. & - & - & - & - & 35 & 12 & 1 & - & - \\
\hline $\mathrm{N}=48$ & $\%$ & & & & & 72.9 & 25.0 & 2.1 & - & - \\
\hline Penicillin & No. & - & - & - & 50 & 2 & 10 & 4 & 6 & - \\
\hline No. $=72$ & $\%$ & - & - & - & 69.4 & 2.75 & 13.9 & 5.5 & 8.25 & - \\
\hline
\end{tabular}

*No. $=$ number tested

A majority of the coagulase negative strains were resistant to ampicillin, colistin and erythromycin. The MIC of penicillin, ampicillin and erythromycin for the $S$. aureus isolates are shown in Table 5. The MIC of penicillin $\mathrm{G}$ for majority of the isolates was $2.0 \mu \mathrm{g} / \mathrm{ml}$ whereas the MIC of ampicillin for most strains was $8.0 \mu \mathrm{g} / \mathrm{ml}$. Thirty five isolates had MIC of $8.0 \mu \mathrm{g} / \mathrm{ml}$ and twelve had MIC of $4.0 \mu \mathrm{g} / \mathrm{ml}$ for erythromycin.

\section{DISCUSSION}

Enterotoxin-producing $S$. aureus is a common cause of staphylococcal food poisoning characterised by diarrhoea. In Nigeria, the true prevalence of $S$. aureus diarrhoea could not be ascertained given that most cases are not reported to health institutions. There is therefore insufficient epidemiological data for proper estimation of $\mathrm{S}$. aureus diarrhoea. In the present investigation, most infants below one year of age were fed with breast milk while those above one year, in addition to breast-feeding, were fed other foods, all of which could be vehicles for the consumption of preformed toxins produced by $S$. aureus and hence produce diarrhoea.

It was observed that $37(60.7 \%)$ of the enterotoxigenic strains of $S$. aureus in this study produced enterotoxin A. This agreed with several reports in the literature. Wieneke et al. (11) in their study of staphylococcal food poisoning in the United Kingdom between 1969 and 1990 reported that strains of S. aureus from $79 \%$ of incidents of staphylococcal food poisoning produced enterotoxin A alone or together with another enterotoxin. In this study 37(51.4\%) produced enterotoxin A alone and 12(16.7\%) produced enterotoxin $\mathrm{A}$ in combination with other enterotoxins (Table 4). Levine et al(12) also reported staphylococcal enterotoxin A in staphylococcal food poisoning involving canned mushrooms. Most food poisoning outbreaks involve enterotoxin A and D (13), which is not surprising as these enterotoxins are produced over the wide range of environmental conditions pertaining in food. SEA is the enterotoxin most commonly produced 
by $S$. aureus from human sources. However Adesiyun et al.(14) reported that the majority of $S$. aureus strains from adults with diarrhoea elaborated enterotoxin $\mathrm{C}$. Only in six strains were enterotoxin $\mathrm{C}$ produced in the present investigation, and where this was the case it was in combination with some other enterotoxins. Enterotoxin D was the second most frequently produced enterotoxin in this study. It has been reported that $S$. aureus strains which produce SEC and SED may be predominant in raw milk and milk products (15). Pereira et al(16) reported that although enterotoxin D was produced in small amounts than other enterotoxins in laboratory media, staphylococcal strains producing enterotoxin $\mathrm{D}$ can produce sufficient enterotoxin in foods to cause food poisoning. There were no clonal relationships between the different enterotoxinproducing isolates. This is expected since the isolates were from cases of sporadic diarrhoea. No vomiting was observed in all the children studied whereas confirmed outbreaks have always involved diarrhoea with vomiting (17). Although enterotoxin positive and coagulase negative variants of staphylococci had been reported in the literature(18), the production of enterotoxin was not observed in coagulase-negative strains isolated in this study. Of the $72 \mathrm{~S}$. aureus isolates $61(85 \%)$ were lysed by phage of group III while seven and four of the remaining strains were susceptible to phages of group I and 95 respectively. There was strong association between production of enterotoxin A and phage group III isolates, enterotoxin $\mathrm{C}$ and phage type 95 isolates.

Of the eleven antimicrobials used, $S$. aureus strains were predominantly resistant to penicillin G. All the enterotoxin producers were resistant. When strains were reviewed closely, strong associations were observed between production of enterotoxin $\mathrm{A}$ and MIC of between 0.5 and $8.0 \mu \mathrm{g} / \mathrm{ml}$ for penicillin, enterotoxin D production and MIC of between 1.0 and $4.0 \mu \mathrm{g} / \mathrm{ml}$ for ampicillin. Five isolates of methicillin resistant $S$. aureus (MRSA) were detected among the staphylococcal population. MRSA are important nosocomial pathogens, hence further study may be required to determine their importance in sporadic diarrhoea affecting children. The MRSA isolates recovered in this investigation were from the same hospital. Results from the antibiotic resistance profiles revealed that the use of chloramphenicol, gentamicin, cephalothin and clindamycin would be appropriate for the management of food-borne diarrhoea caused by S.aureus after the clinical value of these antibiotics in young children and infants has been determined.

\section{REFERENCES}

1. Bean, N.H. and Griffin, P.M. Food borne disease outbreaks in the United States 1973-1987: pathogens, vehicles and trends. J. Food Protect. 1990; 53: 804-817.

2. Adekeye, J. D . and Adesiyun, A.A. Frequency of isolation of enterotoxigenic staphylococi from milk of nursing mothers in Kaduna, Nigeria. J. Hyg. 1984; 93: 531-538.

3. Olowe, S.A., Ahmed, I., Lawal, S.F. and RansomeKuti, S. Bacteriological quality of raw milk: effect of storage in a refrigerator. Ann. Trop. Paediatr. 1987; 7: 233-237.

4. Adetosoye, A.I. Transmissible drug resistance in humans and animals strains of Enterobacteriaceae and Pseudomonas aeruginosa. Res. Vet. Sci. 1980; 29: 342-345.

5. Barrow, G.I. and Feltham, R.K.A. (eds). Cowan and Steel's Manual for the identification of medical bacteria, 3rd edition, University Press, Cambridge; 1993.

6. Adegoke, G.O. Plasma coagulation and extracellular products of caprine strains of S. aureus. Bull. Anim. Hlth. Prod. Afr. 1987; 35:1-15.

7. Devriese, L.A., Vlaminck, K., Nuytten, J. and de Keersmaecker, P.H. Staphylococcus hyicus in skin lesions of horses. Equine. Vet. J. 1983; 15: 263-265.

8. Adetosoye, A.I., Adegoke, G.O. and Ayoade, G.O. Characteristics of streptococci and staphylococci isolated from cows with mastitis at Iwo Road Dairy, Ibadan, Nigeria and the enterotoxigenicity of B. cereus isolated from cheese made from the dairy cows. Bull. Anim. Hlth. Prod. Afr. 1986; 34:185-189.

9. National Committee for Clinical Laboratory Standards. Performance Standards for Antimicrobial Disk Susceptibility Tests 5th edition Villanova, PA. 1993.

10. Adetosoye, A.l., Willinger, H. and Awad, M.M. Characterization of haemolytic colicinogenic Escherichia coli isolated from diarrheic piglets: J. Nig. Vet. Med. Assoc. 1977; 5: 45-49.

11. Wieneke, A.A., Roberts, D. and Gilbert, R.J. Staphylococcal food poisoning in the United Kingdom, 1969-1990. Epidemiol. Infect. 1993; 110: 519-531.

12 Levine, W. C., Bennett, R.W., Choi. Y., et al. Staphylococcal food poisoning caused by imported canned mushrooms. J. infect. Dis. 1994; 173: 1263-1267.

13. Baird-Parker, A.C. The staphylococci: an introduction. J. Appl. Bacteriol. (Sympo. Suppl). 1990; 69:15-85.

14. Adesiyun, A.A., Lenz, W. and Schaal, P. Phage susceptibility, enterotoxigenicity and antibiograms of Staphylococcus aureus isolated from human wounds and diarrhoea. Int. J. Med. Microbiol. Virol. Parasitol. Infect. Dis. 1992; 277: 250-259.

15. Payne, D.N. and Wood, J.N. The incidence of enterotoxin production in strains of Staphylococcus aureus isolated from foods. J. Appl. Bacteriol. 1974; 37: 319-325.

16. Pereira, J.L., Salzberg, S.P. and Bergdoll, M.S. Production of staphylococcal enterotoxin D in foods by low-enterotoxin producing staphylococci. Int. J. Food Microbiol. 1991; 14: 19-25.

17. Holmberg, S.D. and Blake, P.A. Staphylococcal food poisoning in the United States. J. Amer. Med. Asso. 1984; 251:487-489.

18. Mossels, D.A. and van Netten, P. Staphylococcus aureus and related staphylococci in foods: ecology, proliferation, toxinogenesis, control and monitoring. J. Appl. Bacteriol. Suppl. 1990; 69:1235-1465. 